\title{
THE CARBOXYLMETHYLATION OF CEREBRAL MEMBRANE-BOUND PROTEINS INCREASES WITH AGE
}

\author{
OTTO Z. SELLINGER, CRAIG M. KRAMER, ALICIA CONGER and \\ GREGORY S. DUBOFF* \\ Laboratory of Neurochemistry, Mental Health Research Institute, University of Michigan Medical \\ Center, Ann Arbor, MI 48109 (U.S.A.)
}

(Received October 6th, 1987)

(Revision received December 3rd, 1987)

\section{SUMMARY}

Recently, we have characterized a membrane-bound (mb) component of brain protein carboxylmethyltransferase II (PCMT) which effectively carboxylmethylates endogenous mb methyl-accepting proteins (MAPs). (Neurochem. Int., 10 (1987) 155). We have also shown that exposing mb-MAPs to mild alkali leads to a marked increase in their recognition by PCMT. Since one of the likely consequences of the alkaline treatment appears to be the deamidation of selected protein-bound asparagines or aspartates, followed by the formation, in their place, of D-or Lisoaspartates, it is reasonable to assume that mb-MAPs constitute unique targets for the mb-PCMT because they contain such unnatural aspartate residues. Testing the relevance of this notion to the aging of cerebral mb-MAPs we focus in this report on age-related changes involving mb-MAPs. When two-or six-times washed (in $50 \mathrm{mM}$ $\mathrm{NaPO}_{4}$ buffer, pH 6.5) $17500 \mathrm{~g}$, 30-min membranes or Percoll-gradient purified synaptic membranes were prepared from young (3-4 months) and old (11-12 months) rat brains and were incubated with $20 \mu \mathrm{M}\left[{ }^{3} \mathrm{H}\right]$ methyl $S$-adenosyl-Lmethionine at $\mathrm{pH} 6.0$, mb-MAP carboxyl[ $\left.{ }^{3} \mathrm{H}\right]$ methylation was significantly more intense in the old than in the young membranes, no additional increase being noted at 28-35 months. Mb-MAP carboxylmethylation increases were confirmed over a wide range of membrane protein concentrations and incubation times and are taken to reflect age-related modifications of the primary structure of susceptible mbMAPs. To investigate these, we incubated young and old membranes, as well as their Lubrol- $\mathrm{P}_{x}(1 \%)$ extracts $\left(30 \mathrm{~min}, 0^{\circ} \mathrm{C}\right)$, with $0.05 \mathrm{M} \mathrm{NH}_{4} \mathrm{OH}$ for $90 \mathrm{~min}$ at $37^{\circ} \mathrm{C}$, a treatment which left PCMT activity largely unaffected. Our findings reveal

*Handicapped Scientist, supported by the Michigan Commission for the Blind Rehabilitation Services. Abbreviation: SAM, S-adenosyl-L-methinonine. 
that the effect of the $\mathrm{NH}_{4} \mathrm{OH}$ treatment on the generation of carboxylmethylatable sites was markedly smaller in "old" than in "young" proteins, suggesting that "new" carboxylmethylatable sites are generated in susceptible mb-MAPs in situ, by a process accompanying, or otherwise marking, the natural aging of neural membrane proteins.

Key words: Brain; Protein carboxylmethylation; Membranes

\section{INTRODUCTION}

Although the process of cellular aging is admittedly highly complex, [1] evidence is accumulating to suggest that it has a molecular basis and, hence, that it may be profitably studied through investigations of the aging of intracellular proteins. Several types of modification may be incurred by proteins residing in aging cellular systems [2,3] and part of the relevant research has recently been summarized [4-6]. One type of an enzyme-catalyzed age-related protein modification is its carboxylmethylation. The cognate enzyme, protein carboxylmethyltransferase II (EC. 2.1.1.24) (PCMT) [7,8], appears to recognize only those proteins in which, via biological mechanisms still incompletely understood $[9,10]$, selected L-aspartate residues have been replaced by D-aspartate [11] and/or L- or D-isoaspartate [1215]. Although several reports associating the presence of protein-bound D-aspartate with aging have appeared, [16-19] there is no unambiguous evidence for the presence of unnatural isoaspartates in proteins of either young or aged cells.

Recently we have characterized in some detail a membrane-bound (mb) component of brain PCMT [20,21] which effectively carboxylmethylates mb methyl-accepting proteins (MAPs). We have also shown that exposing mb-MAPs or their Lubrol- $P_{x}$ extracts to mild alkali leads to a marked increase in their recognition by PCMT [22]. Since, in vitro, one of the likely consequences of the mild alkaline treatment appears to be the deamidation of selected protein-bound asparagines [23], and/or aspartates [24], followed by the formation, in their place, of unnatural isoaspartate(s) $[25,26]$, it is reasonable to assume that mb-MAPs constitute unique targets for the mb-PCMT, because they contain unnatural aspartate residues. In the present report, we test the relevance of this notion to the aging of cerebral mb-MAPs and find that, in the rat, their treatment with mild alkali results in the generation of significantly fewer protein-bound sites susceptible to carboxylmethylation by the mb-PCMT in middle age and very old brains, than in young brains. Based on this and other findings, also part of this report, we propose that, as selectively vulnerable asparagine and/or aspartate residues of specific brain mb proteins progressively convert to unnatural aspartate forms in situ, the resulting increase in their carboxylmethylatability in vitro may represent a useful marker with which to trace the time course of their aging. 


\section{MATERIALS AND METHODS}

$S$-adenosyl-L-methionine (di-p-toluenesulfonate salt) was a gift from Dr. G. Stramentinoli, BioResearch, Liscate, Italy. Crystalline ovalbumin, bovine serum albumin, Lubrol- $P_{x}$, Coomassie Blue and Percoll were from Sigma. The MW standards for electrophoresis were from Pharmacia. Acrylamide and $N,-N^{\prime}$-bismethylene acrylamide were from Serva. $\mathrm{En}^{3}$-Hance was from New England Nuclear. $\left[{ }^{3} \mathrm{H}\right]$ methyl $S$-adenosyl-L-methionine $(1 \mathrm{mCi} / \mathrm{ml})$ with a nominal specific radioactivity of $10-15 \mathrm{Ci} / \mathrm{mmol}$ was from $\mathrm{ICN}$. All other reagents were of the best analytical grade available.

\section{Animals}

Rats were Sprague-Dawley, Charles River males purchased from the local vendor (Portage, Michigan). They were $2-4$ (young), 11-12 (middle age) and 2835 (very old) months old.

\section{Preparation of fractions}

Rat cerebra were homogenized in about 10 vols. of ice-cold $50 \mathrm{mM} \mathrm{NaPO}_{4}$ buffer (pH 6.5) and the homogenate centrifuged at $17500 \mathrm{~g}$ for $30 \mathrm{~min}$. The large pellet was re-homogenized mechanically (8-10 up-and-down strokes) using a Teflon-tipped pestle rotating in a glass homogenizing tube at approximately $1200 \mathrm{rev} . / \mathrm{min}$. Pellet No. 2 was obtained by centrifuging as above. This pellet, one washed six times, or a pellet consisting of highly purified synaptic membranes (see below) were the source of the mb-PCMT-MAP system used throughout the study. Synaptosomes were prepared according to Nagy and Delgado-Escueta [27]. The collected gradient bands (10\%-16\% Percoll interface) from several tubes were sedimented at $105000 \mathrm{~g}$ for $45 \mathrm{~min}$ and the pellet containing the synaptosomes was resuspended by manual homogenization in $3 \mathrm{ml}$ of $50 \mathrm{mM} \mathrm{NaPO}_{4}$ buffer $\left(\mathrm{pH} \mathrm{6.5)}\right.$ for $30 \mathrm{~min}$ at $0^{\circ} \mathrm{C}$. Synaptic membranes were collected by centrifugation at $105000 \mathrm{~g}$ for $20 \mathrm{~min}$. They were washed once, before resuspension and aliquoting into $1-\mathrm{ml}$ portions followed by freezing or immediate use.

\section{Analytical}

Protein was determined according to Peterson [28], with crystalline bovine serum albumin as standard.

\section{Acidic slab gel electrophoresis}

The procedure described by Aswad and Deight [29] was used. A vertical slab gel system (SE-400, Hoefer Scientific), powered by $180 \mathrm{~V}$ for $3.5 \mathrm{~h}$ at room temperature provided the desired separations. After electrophoresis, portions of the slabs containing the radioactive proteins were treated with $\mathrm{En}^{3} \mathrm{Hance}$ according to the vendor's instructions and were immediately dried in a slab gel drier (Pharmacia, 
GSD-4) at 32v, 1 amp for $2.5 \mathrm{~h}$ before being placed in contact with XAR-5 X-ray film for exposure at $-70^{\circ} \mathrm{C}$. The non-radioactive proteins, run in parallel lanes, were stained with $0.25 \%(\mathrm{w} / \mathrm{v})$ Coomassie Blue for $30 \mathrm{~min}$ and were then destained in $7 \%(\mathrm{v} / \mathrm{v})$ acetic acid.

\section{The assay of PCMT activity}

(a) Acting on endogenous $m b-M A P s$. The procedure of Diliberto and Axelrod [30] was used. Each tube $(255 \mu \mathrm{l})$ contained 5-10 $\mu$ curies of $\left[{ }^{3} \mathrm{H}\right]$ methyl SAM and the following, at the final concentration: phosphate-citrate buffer (pH 6.0), $50 \mathrm{mM}$; SAM, $20 \mu \mathrm{M}$; EDTA, $0.4 \mathrm{mM}$; dithiothreitol, $1.2 \mathrm{mM}$ and tissue, up to $200 \mu \mathrm{l}$ [22]. Unless otherwise stated, the incubation was for $30 \mathrm{~min}$ at $37^{\circ} \mathrm{C}$. Carboxylmethylation was arrested by the addition of $1 \mathrm{ml}$ of $20 \%(\mathrm{w} / \mathrm{v})$ TCA followed by $1 \mathrm{mg}$ of BSA as carrier. After $15 \mathrm{~min}$ on ice, the tubes were centrifuged at $3400 \mathrm{rev} . / \mathrm{min}$ for $15 \mathrm{~min}$. The pellets were suspended in $0.5 \mathrm{ml}$ of $0.125 \mathrm{M}$ "borax" $\left(\mathrm{Na}_{2} \mathrm{~B}_{4} \mathrm{O}_{7}-10 \mathrm{H}_{2} \mathrm{O}\right)(\mathrm{pH} 10.7)$, and were incubated for $5 \mathrm{~min}$ at $37^{\circ} \mathrm{C}$. After the addition of $1.2 \mathrm{ml}$ of a $3: 2(\mathrm{v} / \mathrm{v})$ mixture of toluene: isoamyl alcohol, the tubes were thoroughly vortexed and centrifuged at $4000 \mathrm{rev} . / \mathrm{min}$ for $5 \mathrm{~min}$. Two $0.5-\mathrm{ml}$ aliquots of the upper phase, containing the released $\left[{ }^{3} \mathrm{H}\right] \mathrm{CH}_{3} \mathrm{OH}$ were placed into 2 scintillation vials for determination of the total and the carboxyl- $\left[{ }^{3} \mathrm{H}\right]$ methyl radioactivity.

(b) Acting on ovalbumin. The above assay was carried out in the presence of $100 \mu \mathrm{g}$ of ovalbumin.

(c) $m b-P C M T$ activity. PCMT activity is expressed as pmol of $\left[{ }^{3} \mathrm{H}\right]$ methyl transferred from $\left[{ }^{3} \mathrm{H}\right]$ methyl SAM to the endogenous mb-MAPs or, when ovalbumin was present, to the sum of the mb-endogenous MAPs + ovalbumin. PCMT specific activity (spec. act.) is defined as activity $/ \mathrm{mg}$ of protein.

(c) The mild alkaline treatment. Six-times washed membrane pellets were resuspended in $50 \mathrm{mM} \mathrm{NaPO}$ buffer (pH 6.5), containing the mb-PCMT-MAP system [22] and were then treated with $0.05 \mathrm{M} \mathrm{NH}_{4} \mathrm{OH}$ (see below) or, first, with $1 \%$ Lubrol- $\mathrm{P}_{x}$ at $0^{\circ} \mathrm{C}$ for $30 \mathrm{~min}$. In the latter case, following centrifugation at $17500 \mathrm{~g}$ for $30 \mathrm{~min}$, the resulting supernatant $\left(\mathrm{S}_{\mathrm{L}}\right)$ and pellet $\left(\mathrm{P}_{\mathrm{L}}\right)$, (resuspended in $50 \mathrm{mM}$ $\mathrm{NaPO}_{4}$ buffer ( $\mathrm{pH} 6.5$ )), were incubated in the presence of $0.05 \mathrm{M} \mathrm{NH}_{4} \mathrm{OH}$ for $90 \mathrm{~min}$ at $37^{\circ} \mathrm{C}$, alongside controls containing no ammonia. The $\mathrm{pH}$ of all of the samples was re-adjusted to 6.5 with $1 \mathrm{M}$ acetic acid (requiring 35-45 and 3-4 $\mu \mathrm{l}$ for the alkali-exposed and the control samples, respectively) and the amount of $\mathrm{NH}_{4} \mathrm{OH}-$ generated mb-MAPs was then determined in the standard assay. Separate experiments established that the above $\mathrm{NH}_{4} \mathrm{OH}$ treatment caused no loss of PCMT activity, thus obviating the necessity to use the purified cytosolic PCMT for the quantitation of the $\mathrm{NH}_{4} \mathrm{OH}$-generated mb-MAPs.

RESULTS

Initially, the time course $(10-120 \mathrm{~min})$ of carboxyl- $\left[{ }^{3} \mathrm{H}\right]$ methylation of mbMAPs by the mb-PCMT was compared in six-times washed membranes of young 
and very old brains. The results (data not shown) of these experiments clearly demonstrated higher levels of carboxylmethylation in the very old animals' brains. Thus, after 60 and 120 min of incubation, respectively, we consistently found 10 15 and $20-25 \mathrm{pmol}$ of $\left[{ }^{3} \mathrm{H}\right]$ methyl transferred to mb-MAPs in the very old, vs. $6-7$ and 9-12 pmol in the young brains. Interestingly, however, a similar comparison of the mb-PCMT-MAP system (15-180 min of incubation) between synaptic membranes [27] of young and middle age brains revealed no significant differences in carboxylmethylation, whether this was tested in fresh or once liquid nitrogen frozen-thawed membrane preparations (O.Z. Sellinger and S. Fielek, unpublished observations).

The significantly higher levels of protein carboxylmethylation in the six-times washed membranes of the very old brains are further illustrated in Fig. 1.

[SAM]-dependent differences in carboxyl-[ $\left.{ }^{3} \mathrm{H}\right]$ methylation between mb-MAPs of young and very old six-times washed membranes are illustrated in Fig. 2. Since more $\left[{ }^{3} \mathrm{H}\right]$ methyl appeared to be transferred to mb-MAPs in the older membranes, a higher apparent $V_{\max }$ value for SAM obtained; however, given our inability to date to identify the nature, number and molecular characteristics of the individual proteins

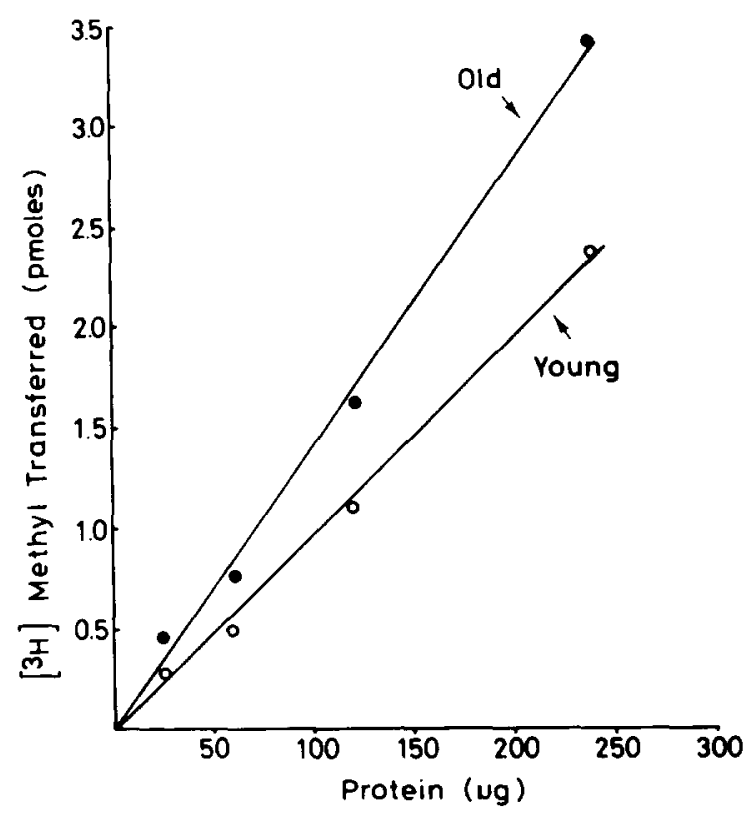

Fig. 1. The effect of membrane protein concentration on the carboxyl-[ $\left.{ }^{3} \mathrm{H}\right]-$ methylation of brain MAPs. Six-times washed membranes were prepared (see Methods) from brains of a young (65 days) and an old (341 days) rat. Suspensions containing the amounts of protein indicated were incubated for $60 \mathrm{~min}$ in the standard assay (see Methods). The values on the ordinate refer to the number of pmol transferred from $\left[{ }^{3} \mathrm{H}\right] \mathrm{SAM}$ to acceptor proteins during the incubation. In three consecutive experiments the difference between old and young was within $15-20 \%$ of the values shown, favoring the old membranes. 


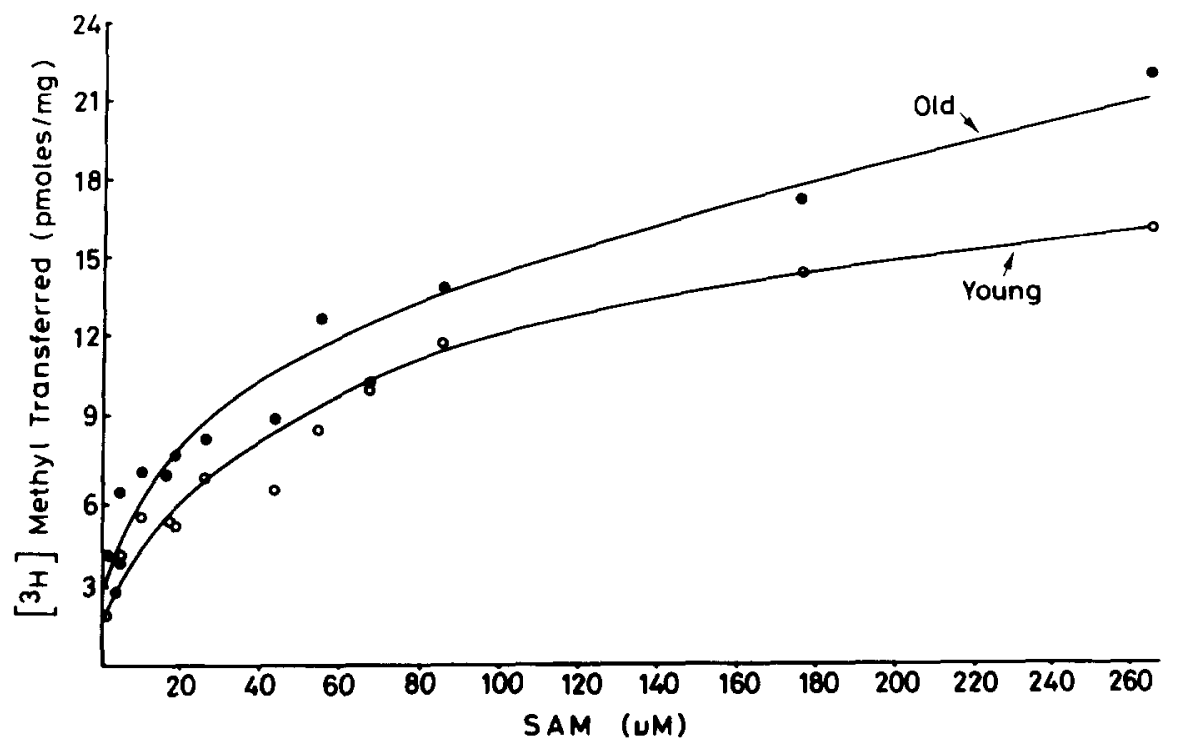

Fig. 2. The effect of varying the concentration of SAM on the carboxylmethylation of rat brain mbMAPs. The graphs shown are a composite of three separate experiments at each age, in each of which the effect of at least five different concentrations of SAM was compared in the presence of $456 \mu \mathrm{g}$ of young (65 days) and $467 \mu \mathrm{g}$ of old (341 days) membrane protein. Incubations were for $30 \mathrm{~min}$ in the standard assay (see Methods).

being carboxylmethylated i.e. of the mbMAPs, we refrain from expressing the relevant $V_{\max }$ values for [SAM] numerically.

A comparison of the PCMT activity in two- vs. six-times washed membranes of young, middle age and very old rat brains is presented in Table 1. Although the specific activity of the endogenous mb-[ $\left.{ }^{3} \mathrm{H}\right]$ MAPs (experiment 1) diminished at all ages as the concentration of protein in the incubates increased, its absolute value was significantly higher at $11-12$ than at 2-4 months at each concentration of protein tested. Conversely, there was little additional change in the specific activity of the mb- $\left[{ }^{3} \mathrm{H}\right]$ MAPs between $11-12$ and $28-35$ months of age. Further evidence for the middle age onset of the increase in mb-MAP carboxyl- $\left[{ }^{3} \mathrm{H}\right]$ methylation is provided by the marked increase $(78 \%)$ of the specific activity of mb-[ $\left.{ }^{3} \mathrm{H}\right]$ MAPs at $11-12$ months relative to that noted at $2-4$ months (experiment 2 ), with no further increase at 28-35 months. The findings of experiments 3 and 4 (Table I) also reveal the specific activity of the mb- $\left[{ }^{3} \mathrm{H}\right] \mathrm{MAPs}$ to be clearly higher at $28-35$ months than at 2-4 months, both before (experiment 3 ) and after solubilization (experiment 4) of the relevant MAPs. When assayed in the presence of ovalbumin (Table I), BSA or calmodulin (data not shown), levels of mb-PCMT activity showed no consistent agerelated fluctuations.

The effect of treating proteins of young and very old rat brain membranes with 


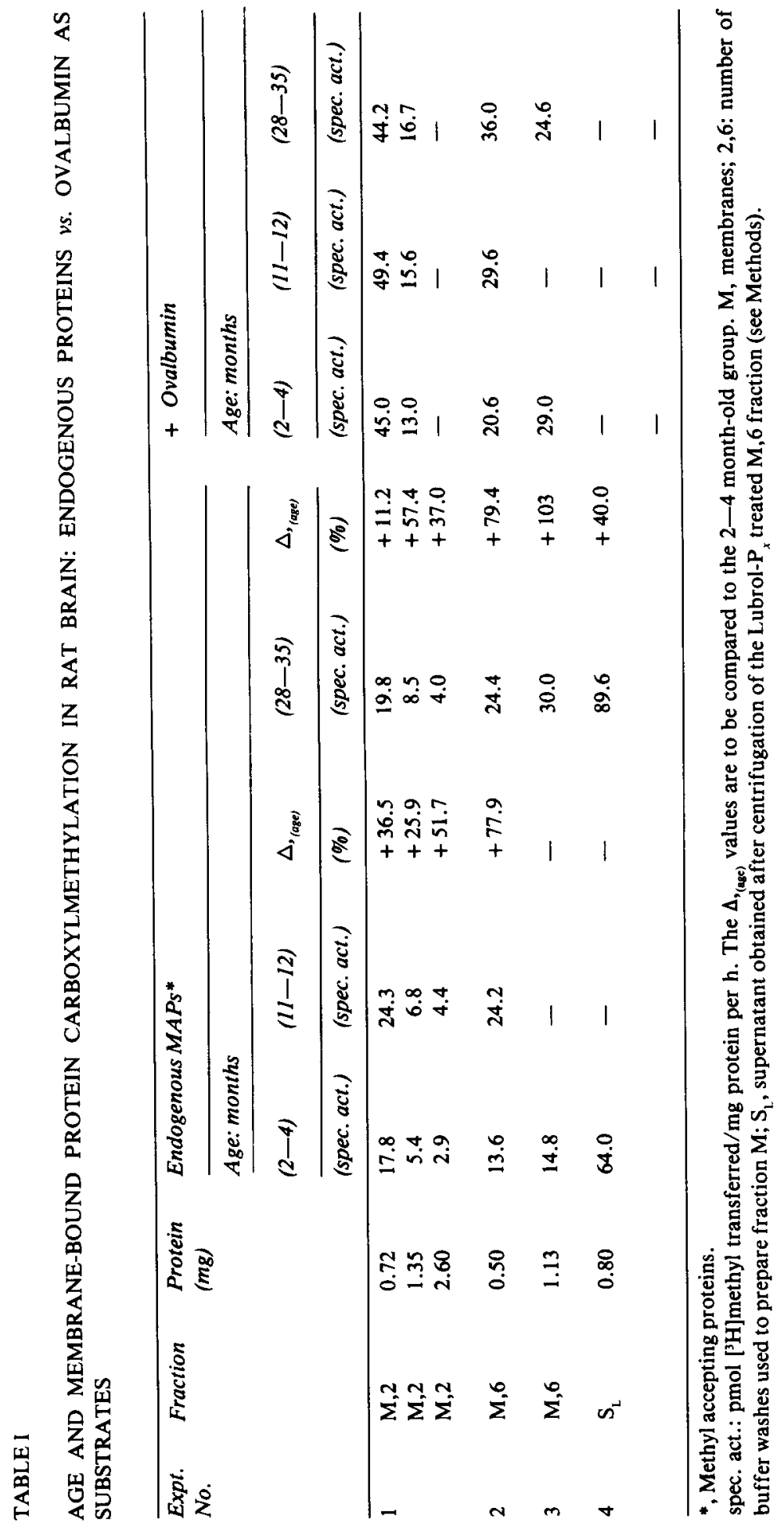




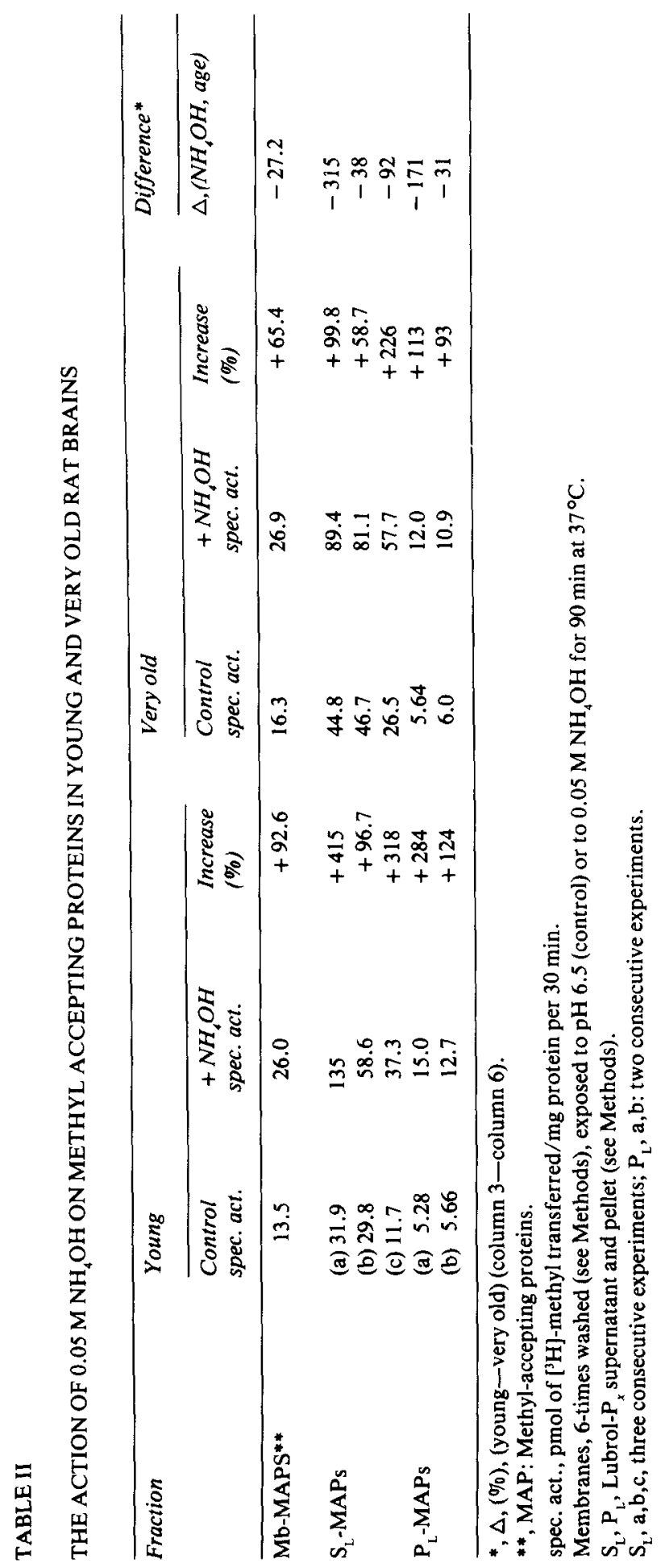



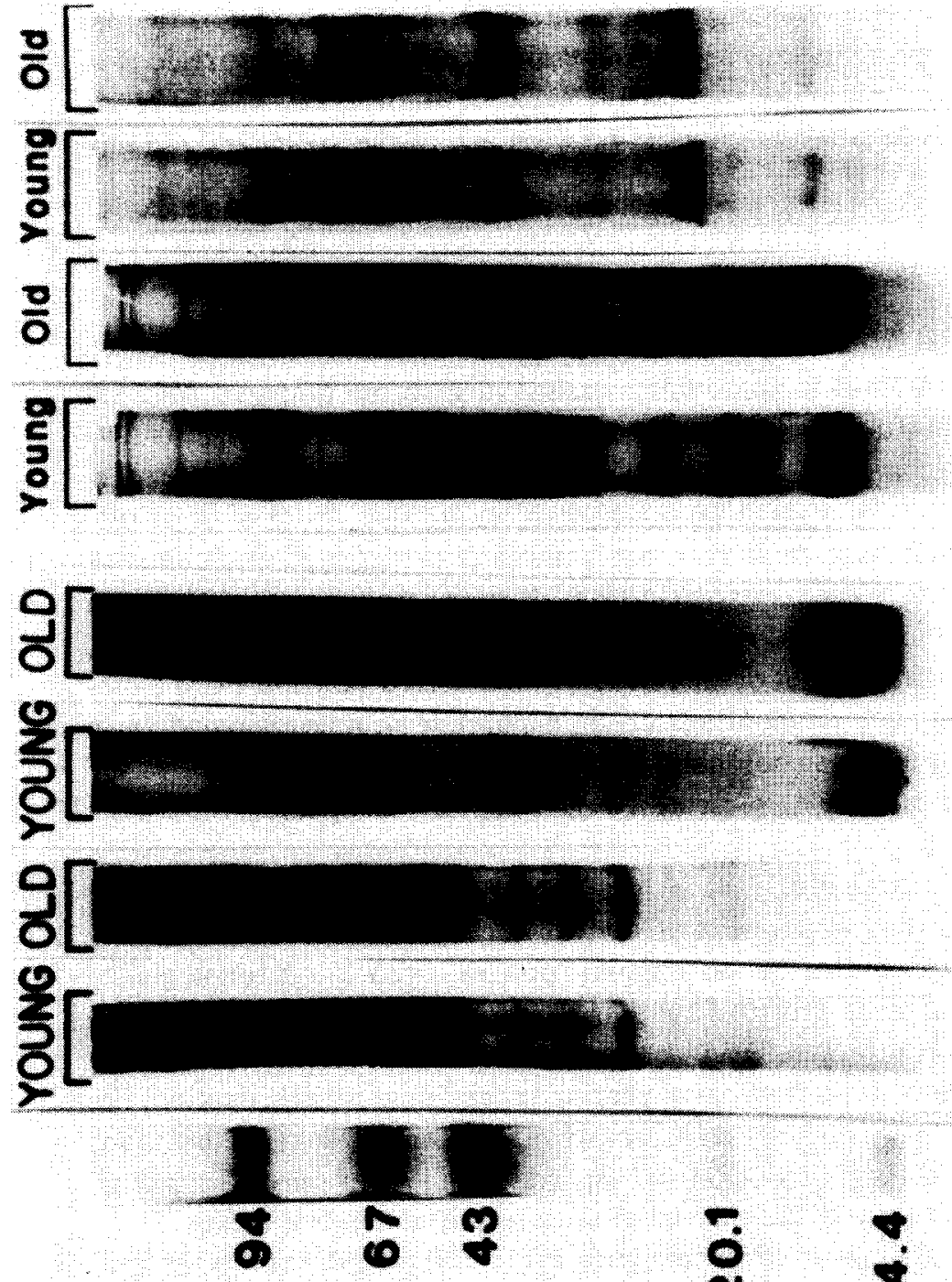

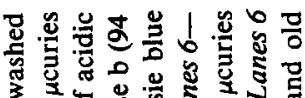

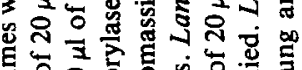

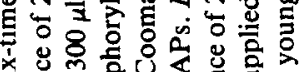
x.

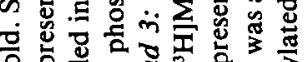

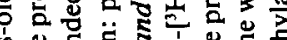

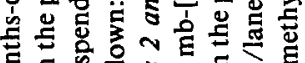
응 돈

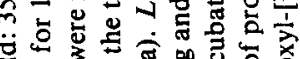

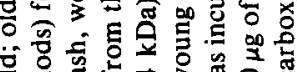

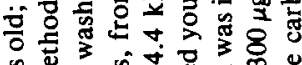

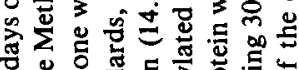

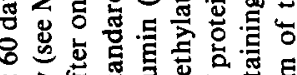
i。

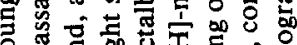
$\succ$ 둥

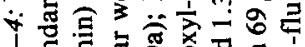

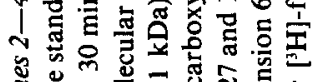

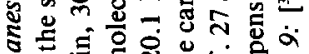

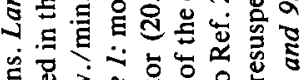

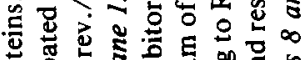

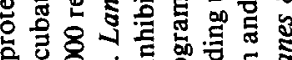

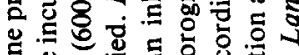

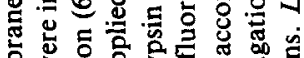

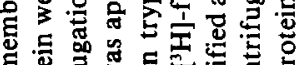

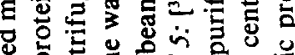

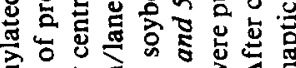

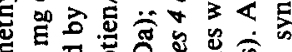
可娣

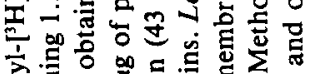

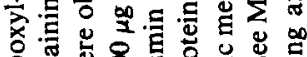
尊

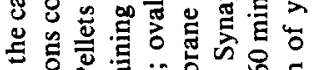

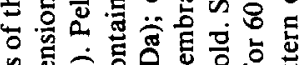

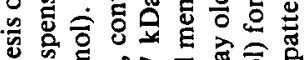

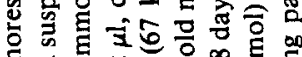

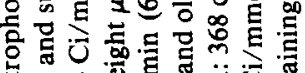
政品

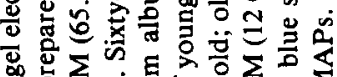

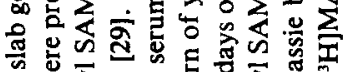

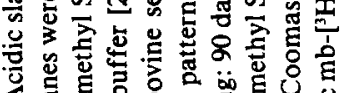

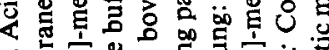

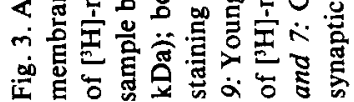


$0.05 \mathrm{M} \mathrm{NH}_{4} \mathrm{OH}$ for $90 \mathrm{~min}$ at $37^{\circ} \mathrm{C}$ was tested next. Table II shows that (a) mb$\left[{ }^{3} \mathrm{H}\right] \mathrm{MAPs}$ were generated in the unfractionated membranes and in the Lubrol$P_{x}$-derived subfractions, $S_{L}$ and $P_{L} ;(b)$ a greater number of MAPs appeared after the $\mathrm{NH}_{4} \mathrm{OH}$ treatment in the young than in the very old brains and, consequently, (c) there was a significant reduction in the magnitude of the $\mathrm{NH}_{4} \mathrm{OH}$ effect in the very old, relative to the young brains. The uniformly negative $\Delta_{\left(\mathrm{NH}_{4} \mathrm{OH}, \text { age }\right)}$ values shown in the last column of Table II are a quantitative expression of these findings. Figure 3 illustrates the young $v s$. old banding pattern of the proteins in the six-times washed membranes and in the synaptic membranes after Coomassie staining and following 60-min incubation with $\left[{ }^{3} \mathrm{H}\right] \mathrm{SAM}$. The fluorograms reveal fewer than a dozen mb$\left[{ }^{3} \mathrm{H}\right]$ MAPs. Yet, while relative to its young counterpart, the fluorogram of the sixtimes washed old mb proteins shows higher intensities of labelling in the regions of the slowest and fastest migrating species, the synaptic fluorograms fail to reveal discernible differences in labelling intensity between any of the young and old mb[ $\left.{ }^{3} \mathrm{H}\right]$ MAPs.

\section{DISCUSSION}

The present findings document an increase in the carboxylmethylation of methylaccepting proteins contained in thoroughly washed membranes prepared from rat brain at 11-12 months of age, relative to its levels determined at a single earlier (24 months) and a single later (28-35 months) point in life. The observed increase in the intensity of this carboxylmethylation appears to be due, in large measure, although not exclusively, (see Table I, + ovalbumin) to an increased availability of methylatable sites in the relevant mb-MAPs (Fig. 1), rather than in improvements of the ability of the mb-PCMT to recognize preexisting mb-MAPs. We cannot rule out, however, that both components of this newly characterized [22] mb-PCMT-mbMAP system of brain undergo modifications in membrane structuration and/or in chemistry simultaneously, given our inability to date to cleanly dissociate mb-PCMT from its mb-MAP substrates. At present, it would appear that synaptic mb-MAPs are not involved.

As recently noted by Man et al. [19], structural changes in selected proteins of the human brain, such as the racemization of some of their L-aspartate residues to the unnatural D-form, appears to be on ongoing process, with no chronologically precise time-frame; indeed, protein-bound D-aspartate could be detected in the human brain at 10 days post-natally and was noted to peak in or close to midlife (40 -49 years of age). Our present findings appear to be consistent with this notion, i.e. that, in rat brain as well, highest intensities of mb-protein carboxylmethylation, presumed to occur exclusively on unnatural aspartate residues of selected proteins, are reached between $1 / 3$ and $1 / 2$ of this (laboratory-reared) rodent's life span.

The results of preliminary HPLC analyses [31] of the acid hydrolysed mbproteins contained in six-times washed membranes of both young ( $2-4$ months) and 
middle-age (11-12 months) rat brains are in further agreement with such possibilities, as they confirm the natural presence of D-aspartate in both sets of samples (O.Z. Sellinger and C.M. Kramer, unpublished observations).

A chronological relationship between increased protein carboxylmethylation and aging has been demonstrated for proteins of the human erythrocyte $[5,11,16-18]$. Most recently, a detailed study has revealed that intrinsic proteins of the erythrocyte membrane, but not the erythrocyte cytosolic proteins, undergo a most intensive racemization of $\mathrm{L}$ - to $\mathrm{D}$-aspartate and, also, that they accumulate other amino acid residues which form D-aspartate upon acid hydrolysis [16]. The latter have been presumed to include D-asparagine and D-isoaspartate. It is also well established, on the other hand, that L-isoaspartate residues, shown to be effective substrates for PCMT [13-15,24,25] when present in synthetic peptides [24] or when generated in vitro [32], may form from protein-bound L-aspartate or L-asparagine residues [33], via a chemical sequence, the natural occurrence of which would necessitate as a minimum a microenvironment in which foci of local alkalinity would remain sustained over time. It has been shown in this context, and our findings (Table II) prove it for rat brain mb-MAPs, that treatment of MAPs with ammonia $[22,25]$ generates new carboxylmethylatable sites by converting susceptible natural aspartate/asparagines to "atypical" forms of amino acids [5,9]. This test tube reaction may be viewed, therefore, as the single macro event which telescopes, in a very short time and under man-made laboratory conditions, the presumed recurrent micro events which result in situ in net increases of mb proteins containing unnatural aspartate residues. The function of these increments in mb-MAP content per se, in the context of biological aging of membranes or in terms of the indirect effects of such age-induced mb-protein modifications on the behavior of cytoskeletal structures into which mb-MAPs are naturally embedded, is unclear at this time. Our findings (Table II) of a significant reduction in the effectiveness of the ammonia treatment to generate new carboxylmethylatable sites in cerebral mb-MAPs of old, relative to young, six-times washed membranes strongly infers the possibility that modifications similar to those ammonia is able to produce in the test tube, do continue to be generated as young membranes mature, reach middle-age and continue on to become old and very old.

\section{ACKNOWLEDGEMENT}

This research was supported by a grant from the National Institute on Aging, USPHS.

\section{REFERENCES}

B.L. Strehler, Time, Cells and Aging, Academic Press, 1962.

2 R. Strong, Neurochemistry of Aging: 1982-1984. In M. Rothstein (ed.), Rev. Biol. Res. in Aging, Alan R. Liss, vol. 2, 1985, pp. 181-196. 
3 A. Gafni, Age-related modifications in a muscle enzyme. In R.A. Adelman and E.E. Dekker (eds.), Modification of Proteins During Aging, Alan R. Liss, 1985, pp. 19-38.

4 L.L. May-Hoopes, Macromolecular methylation during aging. In M. Rothstein (ed.), Rev. Biol. Res. in Aging, Alan R. Liss, vol. 2, 1985, pp. 361-393.

5 S. Clarke, The role of aspartic acid and asparagine residues in the aging of erythrocyte proteins: cellular metabolism of racemized and isomerized forms by methylation reactions. In Cellular and Molecular Aspects of Aging: The Red Cell as a Model, Alan R. Liss, 1985, pp. 91-103.

6 C.N. Oliver, B. Ahn, M.E. Wittenberger, R.L. Levine and E.R. Stadtman, Age-related alterations of enzymes may involve mixed-function oxidation reactions. In R.A. Adelman and E.E. Dekker (eds.), Modification of Proteins During Aging, Alan R. Liss, 1985, pp. 39-52.

$7 \mathrm{~S}$. Kim, $S$-adenosylmethionine: protein-carboxyl $O$-methyltransferase (Protein Methylase II). In Methods of Enzymology, Academic Press, 1984, Vol. 106, pp. 295-309.

8 S. Clarke, Protein carboxylmethyltransferases: two distinct classes of enzymes. Annu. Rev. Biochem., Annu. Rev., 54 (1985) 479-506.

9 S. Clarke, Protein methylation at abnormal aspartyl residues. In R.T. Borchardt, C.R. Creveling and P.M. Ueland (eds.), Biological Methylation and Drug Design, Humana Press, 1986, pp. 3-14.

10 B.A. Johnson, and D.A. Aswad, Enzymatic protein carboxyl methylation at physiological pH: cyclic imide formation explains rapid methyl turnover. Biochemistry, 24 (1985) 2581-2586.

11 P.N. McFadden and S. Clarke, Methylation at D-aspartyl residues in erythrocytes: possible step in the repair of aged membrane proteins. Proc. Natl. Acad. Sci. (Washington), 79 (1982) 2460-2464.

12 Aswad, D.W. and B.A. Johnson, The unusual substrate specificity of eukaryotic protein carboxylmethyltransferases. Trends Biochem. Sci., 12 (1987) 155-158.

13 P.N. McFadden and S. Clarke, Chemical conversion of aspartyl peptides to isoaspartyl peptides. A method for generating new methyl-accepting substrates for the erythrocyte D-aspartyl/L-isoaspartyl protein methyltransferase. J. Biol. Chem., 261 (1986) 11503-11511.

14 C.M. O'Connor, D.W. Aswad and S. Clarke, Mammalian brain and erythrocyte carboxylmethyltransferases are similar enzymes that recognize both D-aspartyl and L-isoaspartyl residues in structurally altered protein substrates. Proc. Natl. Acad. Sci. (Washington), 81 (1984) 7757-7761.

15 D.W. Aswad, Stoichiometric methylation of porcine adrenocorticotrophin by protein carboxyl methyltransferase requires deamidation at asparagine 25 . Evidence for methylation at the $\alpha$ carboxyl group of atypical L-isoaspartyl residues. J. Biol. Chem., 259(1984) 10714-10721.

16 L.S. Brunauer and S. Clarke, Age-dependent accumulation of protein residues which can be hydrolyzed to D-aspartic acid in human erythrocytes. J. Biol. Chem., 261 (1986) 12538-12543.

17 J.R. Barber and S. Clarke, Membrane protein carboxyl methylation increases with human erythrocyte age. J. Biol. Chem., 258 (1983) 1189-1196.

18 P. Galletti, D. Ingrosso, A. Nappi, V. Gragnaniello, A. Iolascon and L. Pinto, Increased methyl esterification of membrane proteins in aged red-blood cells. Preferential esterification of ankyrin and band-4.1 cytoskeletal proteins. Eur. J. Biochem., 135 (1983) 25-31.

19 E.H. Man, G.H. Fisher, I.L. Payan, R. Cadilla Perezrios, N.M. Garcia, R. Chamburkar, G. Arends and W.H. Frey II, D-Aspartate in human brain. J. Neurochem., 48 (1987) 510-515.

20 O.Z. Sellinger, C.M. Kramer and S.-K. Kim, Changes in brain carboxylmethylation during aging. First Int. Congr. Biomed. Gerontol., New York, 1985, abstract, No. 63.

21 C. Fischer-Bovenkerk, C.M. Kramer and O.Z. Sellinger, Protein carboxylmethylation in the aging brain. Trans. Am. Soc. Neurochem., 17 (1986) 289.

22 O.Z. Sellinger, C.M. Kramer, C. Fischer-Bovenkerk and C.M. Adams, The characterization of a membrane-bound protein carboxylmethylation system in brain. Neurochem. Int., 10 (1987) $155-166$.

23 Y.C. Meinwald, E.R. Stimson and H.A. Scheraga, Deamidation of asparaginyl-glycyl sequence. Int. J. Pep. Protein Res., 28 (1986) 79-84.

24 E.D. Murray, and S. Clarke, Synthetic peptide substrates for the erythrocyte protein carboxyl methyltransferase. J. Biol. Chem., 259 (1984) 10722-10732.

25 B.A. Johnson, N.E. Freitag and D.W. Aswad, Protein carboxyl methyltransferase selectively modifies an atypical form of calmodulin. Evidence for methylation at deamidated asparagine residues. J. Biol. Chem., 260 (1985) 10913-10916. 
26 P.N. McFadden and S. Clarke, Conversion of isoaspartyl peptides to normal peptides: Implications for the cellular repair of damaged proteins. Proc. Natl. Acad. Sci. (Washington), 84 (1987) 2595-2599.

27 A. Nagy and A.V. Delgado-Escueta, Rapid preparation of synaptosomes from mammalian brain using nontoxic isoosmotic gradient material (Percoll). $J$. Neurochem., 43 (1984) 1114-1123.

28 G.L. Peterson, A simplification of the protein assay method of Lowry et al,, which is more generally applicable. Anal. Biochem., 83 (1977) 346-356.

29 D.W. Aswad and E.A. Deight, Endogenous substrates for protein carboxyl methyltransferase in cytosolic fractions of bovine brain. J. Neurochem., 41 (1983) 1702-1709.

30 E.J. Diliberto, Jr. and J. Axelrod, Regional and subcellular distribution of protein carboxymethylase in brain and other tissues. J. Neurochem., 26 (1976) 1159-1163.

31 D.L. Aswad, Determination of D- and L-aspartate in amino acid mixtures by high-performance liquid chromatography after derivatization with a chiral adduct of $o$-phthaldialdehyde. Anal. Biochem., 137 (1984) 405-409.

32 E.D. Murray and S. Clarke, Metabolism of a synthetic L-isoaspartyl-containing hexapeptide in erythrocyte extracts. Enzymatic methyl esterification is followed by nonenzymatic succinimide formation. J. Biol. Chem., 261 (1986) 306-312.

33 A. Di Donato, P. Galletti, and G. D'Alessio, Selective deamidation and enzymatic methylation of seminal ribonuclease. Biochemistry, 24 (1986) 8361-8368. 